\title{
Clinicodemographic Profiles of Rheumatoid Arthritis Patients from a Single Center in Saudi Arabia
}

This article was published in the following Dove Press journal:

Open Access Rheumatology: Research and Reviews

\author{
Yasser Mohammed Bawazir iD \\ Department of Medicine, King Abdulaziz \\ University, Jeddah, Saudi Arabia
}

Purpose: Rheumatoid arthritis (RA), if left untreated, can lead to joint damage and deformity, disability, and even death. Hence, early diagnosis and management are essential to improve clinical and functional outcomes. This study aimed to identify the most common variables and risk factors related to RA activity among patients living in the Kingdom of Saudi Arabia (KSA).

Patients and Methods: This study was conducted between January 2018 and March 2019 on consecutive patients diagnosed with RA at a tertiary care hospital in KSA. Adult patients ( $\geq 18$ years old) diagnosed with RA based on the American College of Rheumatology 2010 criteria were recruited. The Disease Activity Score-28 for Rheumatoid Arthritis with CRP (DAS28-CRP) and health assessment questionnaire disability index (HAQ-DI) were calculated for 75 patients attending the rheumatology clinic during the study period to evaluate the rate of remission and functional capacity, and to compare findings with other local studies after assessing the relationship of these factors with medication use and existing comorbidities.

Results: The majority of the 75 patients were female ( $n=64)$, with a mean age of 49.7 years and average disease duration of 130 days. The median HAQ-DI was less than 0.5 (range $0-1.95$ ). The DAS28-CRP scores revealed moderate disease activity in $45.3 \%$ and low disease or remission in $38.6 \%$ of the patients. Many patients $(45.3 \%)$ were treated with methotrexate, and the most commonly used biological treatment was adalimumab in $14.6 \%$. Comorbidities included hypertension (26.7\%) and diabetes mellitus (18.7\%). There was a strong association between cardiovascular diseases and a high DAS28-CRP score ( $\mathrm{p}<$ $0.001)$.

Conclusion: A higher RA activity rate was observed. This may be related to difficultly accessing rheumatology clinics in our facility and financial difficulties accessing biological treatments.

Keywords: rheumatoid arthritis, DMARD, comorbid conditions, DAS28-CRP, biologics, HAQ-DI

\section{Introduction}

Rheumatoid arthritis (RA) is a chronic auto-immune disease with no cure. However, early diagnosis and treatment with disease-modifying antirheumatic drugs (DMARDs) can help modulate the erosive nature of RA by reducing joint damage and deformity and decreasing the number of flares (periods of high RA disease activity or symptoms). ${ }^{1}$ The European League Against Rheumatism (EULAR) has differentiated the phases through which RA develops. According to the EULAR, the presence of genetic, hormonal, and environmental risk factors leads to RA-related systemic or whole body autoimmunity, starting with symptoms
Correspondence: Yasser Mohammed Bawazir

Department of Medicine, King Abdulaziz University, P.O. Box 80215 , Jeddah, Saudi Arabia

Fax +966 126408347

Email ymbawazir@kau.edu.sa 
without clinical arthritis, then unclassified arthritis, and finally RA. ${ }^{2}$ Bone damage starts before the clinical onset of arthritis in patients with anti-citrullinated protein antibodies (ACPA), during which time clinicians can provide an early diagnosis for patients who are at risk for developing RA and recommend aggressive treatment to control RA. ${ }^{1,3}$

Several cross-sectional, epidemiological studies that assess demographic and clinical variables associated with high RA disease activity are available., ${ }^{4,5}$ Nonetheless, studies in the Kingdom of Saudi Arabia (KSA) have been limited. A literature review on studies of RA in KSA between 2015 and 2019 conducted by Almoallim et $\mathrm{al}^{6}$ identified 43 studies; however, a suboptimal epidemiological result was reported regarding the exact prevalence of RA in the KSA. Hence, the results remain unclear and the review identified only one study published a decade ago involving one particular region and a small sample size.

In 2015, a cross-sectional survey, followed by a clinical assessment, was conducted to estimate the incidence of RA in Taif City, KSA. According to the study by Albishri et $\mathrm{al}^{7}{ }^{7}$ of the 722 completed surveys received, 16 were identified as potential patients with RA, and 12 were confirmed to have RA upon clinical examination, with the majority being female. This increase in the number of RA cases compared to previous estimates could possibly indicate an increasing incidence of RA in the KSA.

A cross-sectional study performed by Almoallim et $\mathrm{al}^{8}$ aimed to identify the most validated variables for indicating an early referral to a rheumatologist by aprimary care physicians (PCP) based on a patient's demographic characteristics, symptoms, physical examination, and biomarkers. The variables that indicated referrals were loss of appetite as well as swelling and tenderness in the joints of the fingers and/or wrist, followed by a positive test for rheumatoid factor and anti-citrullinated protein antibodies. However, the lack of discussion of final diagnosis, small study size, and single-center design limits the generalizability of the study's findings.

A recent article on the use of complementary medicine among RA patients in the KSA revealed that $47 \%$ of participants $\quad(n=293)$ frequently used vitamin D supplementation, followed by calcium supplementation (37\%), and an improved disease activity was found to be significantly higher in patients receiving complementary medicine and those with a higher erythrocyte sedimentation rate (ESR) level. ${ }^{9}$
Another recent multicenter epidemiological study on the prevalence and treatment patterns of RA in five countries, including the KSA and the United Arab Emirates, revealed that educated married women who were nonsmokers with average disease duration of 10 years comprised the majority of the study population. Further, more than $80 \%$ of the patients with RA were prescribed methotrexate (MTX) and steroids. ${ }^{10}$

Based on this literature review, there is still a gap with respect to the identification of valuable predictors of RA based on patient demographics and clinical variables for early diagnosis and optimal management. Hence, in this study, we aimed to identify the most common variables related to RA in the KSA and to assess the rate of disease remission using the Disease Activity Score-28 for Rheumatoid Arthritis with CRP (DAS28-CRP) and health assessment questionnaire disability index (HAQ-DI).

\section{Patients and Methods}

This study was conducted between January 2018 and March 2019 using data from consecutive patients diagnosed with RA in our tertiary care hospital in the KSA. The study was conducted in two phases: the first phase was a retrospective chart review in which patients diagnosed with RA by a rheumatologist, and who fulfilled the ACR/EULAR 2010 classification criteria of rheumatoid arthritis, ${ }^{11}$ were enrolled. Patients with overlap syndrome, coexisting connective tissue disease, and those younger than 18 years old were excluded from the study. In this retrospective phase, several variables collected, including patient demographic data, disease duration, current medications, and comorbidities that developed after the diagnosis of RA, such as cardiovascular disease (CVD), hypertension (HTN), hypothyroidism, osteoporosis, and diabetes mellitus (DM).

The second phase was a comparative cross-sectional study, in which 75 patients selected from the first phase were contacted to visit the clinic for measurement of disease activity and functional capacity. The DAS28-CRP scoring system was used to assess disease activity. This scoring system was validated by the European League Against Rheumatism (EULAR) using the following objective measures: number of tender joints, number of swollen joints, the patient global health assessment, and serum C-reactive protein (CRP). Remission was defined as a score between 0 and $<2.6$, low activity from 2.6 to $<3.2$, moderate activity from 3.2 to $\leq 5.1$, and high activity at $>5.1 .^{12}$ The CRP measurement was collected on the 
same day as the clinic visit using BN II nephelometer technology and a hs-CRP kit (Siemens - Germany).

Functional disability was assessed using the Arabic validated health assessment questionnaire disability index (HAQ-DI). Eight categories with 20 functions, such as dressing, eating, reaching, and walking in the last week, were scored as follows: $0=$ without difficulty, $1=$ with some difficulty, 2 = with much difficulty, and $3=$ unable to perform. Scores were recorded in 0.125 increments. Higher scores indicated worse functional capacity, with 0 indicating no functional impairment and 3 indicating complete impairment. ${ }^{13,14}$

The aim of this study was to assess the RA remission rate in our institution, and compare that with other centers in the region, while also assessing the relationship between the disease activity, functional capabilities, and other comorbidities. We also aimed to elucidate patient demographics and the most common medications used in our center.

This study received ethical approval from the ethics committee of our institution (Reference No. 531-19), written informed consent was obtained from all patients, and the study complied with the Declaration of Helsinki.

\section{Results}

A total of 75 RA patients, 11 males (14.7\%) and 64 females $(85.3 \%)$, were enrolled. The average age of the patients was 49.7 years (range: $21-80$ years) with $56 \%$ of the patients less than 50 years of age. Seropositive disease was identified in 45 patients $(60 \%)$, with a positive rheumatoid factor (RF) in 44 patients (58.6\%) and anticitrullinated peptide antibodies (ACPA) in 40 patients $(53.3 \%)$. The majority $(73 \%)$ of patients were married. The patients had an average of four children; most had at least two children. Furthermore, the majority (79\%) of patients had not had miscarriages, and eight patients had had one miscarriage. When nationality was considered, $55 \%$ of the patients were from Saudi Arabia, 19\% from Yemen, $12.0 \%$ from Africa, $12.0 \%$ from Asia, and 2\% from Palestine and Syria. The average duration of illness was 130 days, with a maximum of 1296 days. The average HAQ-DI score was 0.5 (range $0-1.95$ ). The average TJC and SJC scores were 1. Using the DAS28-CRP to assess the disease activity, we found that $45.3 \%$ of patients were moderately active, $16 \%$ were highly active, and $38.6 \%$ had remission or low activity levels (Table 1 ).

With regards to comorbidities, one patient $(1.3 \%)$ had osteoporosis, indicated by decreased bone mineral density
Table I Demographic Characteristics of the Patients

\begin{tabular}{|c|c|c|}
\hline $\begin{array}{l}\text { Demographic } \\
\text { Characteristics }\end{array}$ & Frequency & $\begin{array}{l}\text { Percentage (\%) } \\
\text { or Range }\end{array}$ \\
\hline \multicolumn{3}{|l|}{ Sex } \\
\hline Male & 11 & 14.7 \\
\hline Female & 64 & 85.3 \\
\hline \multicolumn{3}{|l|}{ Age group (years) } \\
\hline$\leq 42$ & 21 & 28.0 \\
\hline $43-50$ & 21 & 28.0 \\
\hline $5 I-58$ & 16 & 21.3 \\
\hline$\geq 59$ & 17 & 22.7 \\
\hline Mean age (years) (range) & $49.7(21-80)$ & \\
\hline \multicolumn{3}{|l|}{ Children } \\
\hline$\leq 2$ & 29 & 38.7 \\
\hline $3-6$ & 26 & 34.7 \\
\hline$\geq 7$ & 20 & 26.7 \\
\hline Mean (range) & $4(0-12)$ & \\
\hline \multicolumn{3}{|l|}{ Marital status } \\
\hline Single & 12 & 16.0 \\
\hline Married & 55 & 73.3 \\
\hline Divorced & 2 & 2.7 \\
\hline Widowed & 6 & 8.0 \\
\hline \multicolumn{3}{|l|}{ Nationality } \\
\hline Saudi Arabian & 41 & 54.7 \\
\hline African & 9 & 12.0 \\
\hline Palestinian Syrian & 2 & 2.7 \\
\hline Asian & 9 & 12.0 \\
\hline Yemeni & 14 & 18.7 \\
\hline Duration of illness (days) & 129.64 & $1-1296$ \\
\hline (mean $\pm S D)$, range & \pm 162.09 & \\
\hline $\mathrm{HAQ}$ (mean $\pm \mathrm{SD})$, range & $0.62 \pm 0.50$ & $0.00-1.95$ \\
\hline $\begin{array}{l}\text { Tender joint counts (mean } \\
\pm S D \text { ), range }\end{array}$ & $3.84 \pm 5.50$ & $0-20$ \\
\hline $\begin{array}{l}\text { Swollen joint counts (mean } \\
\pm S D \text { ), range }\end{array}$ & $2.4 I \pm 4.26$ & $0-20$ \\
\hline \multicolumn{3}{|l|}{ DAS28-CRP } \\
\hline Low activity/remission & 29 & 38.6 \\
\hline Moderate activity & 34 & 45.3 \\
\hline High activity & 12 & 16 \\
\hline
\end{tabular}

Abbreviations: DAS28-CRP, Disease Activity Score of 28 joints with C-Reactive Protein; HAQ-DI, health assessment questionnaire disability index; SD, standard deviation.

(BMD), eleven (14.7\%) had hypothyroidism, five $(6.7 \%)$ had a history of CVD, specifically ischemic heart disease, fourteen (18.7\%) had DM, 20 (26.7\%) had HTN, and one $(1.3 \%)$ was diagnosed with cancer.

Medication use was as follows: 55 patients (73.3\%) were on conventional DMARDs as a monotherapy or in combination, 34 (45.3\%) used MTX, 24 (32\%) used 


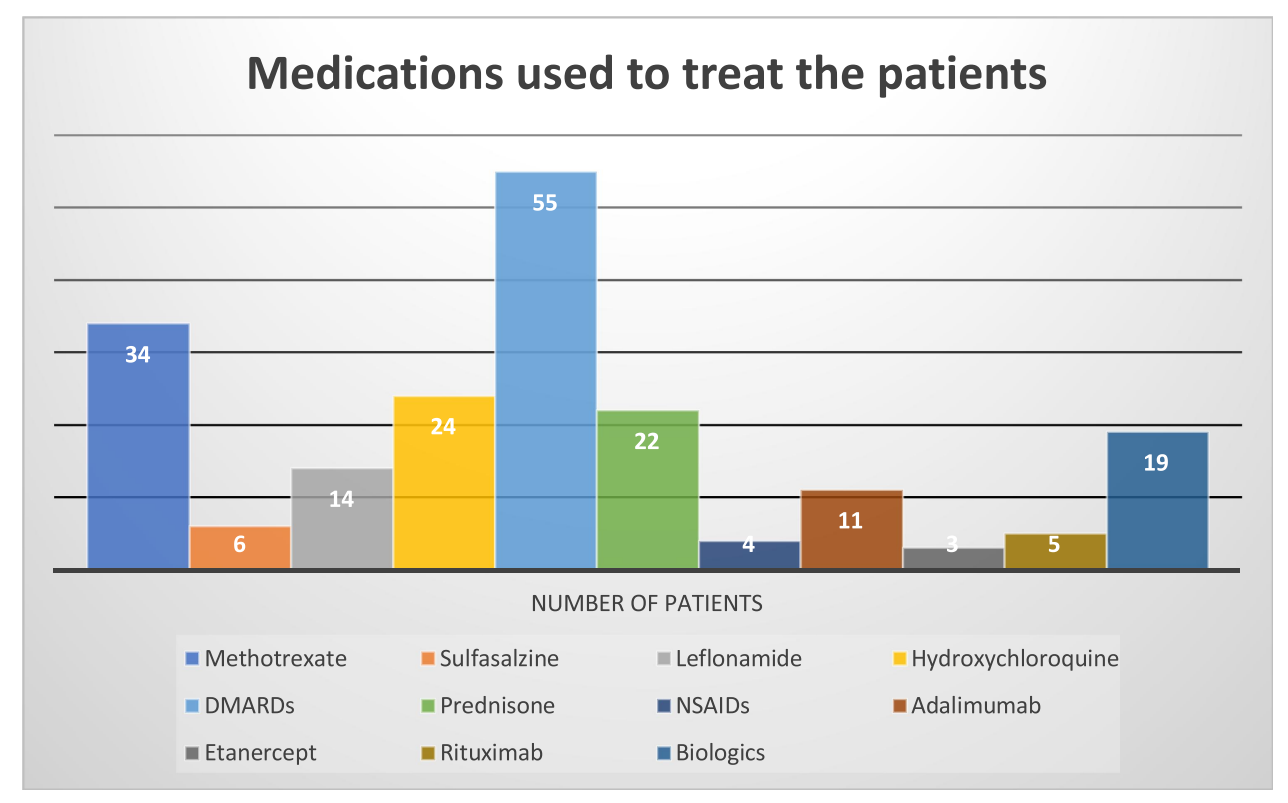

Figure I Schematic representation of the medications used to treat the patients included in the study.

hydroxychloroquine, $6(8 \%)$ were on sulfasalazine, and 14 $(18.6 \%)$ used leflunomide. Some patients required a treatment for acute flares, as a consequence, 22 patients used prednisolone, and 4 patients used nonsteroidal antiinflammatory drugs (NSAIDs) (Figure 1). Nineteen patients received biological treatments as following: 11 on adalimumab, 3 used etanercept, and 5 used rituximab (Table 2).

Using the DAS-28- CRP as an assessment tool for our patients revealed that the majority of the patients, 34 (45.3\%), had moderate disease activity, with 28 patients on DMARDs and 6 on biological treatment, whereas 29 patients had low disease activity or remission, which

Table 2 Medications of the Sample Patients with Rheumatoid Arthritis (Number of Patients)

\begin{tabular}{|l|l|l|l|}
\hline Medications & Monotherapy & Combination & Total \\
\hline DMARDs & 18 & 37 & 55 \\
Methotrexate & 12 & 22 & 34 \\
Leflunomide & 2 & 12 & 14 \\
Sulfasalazine & 1 & 5 & 6 \\
Hydroxychloroquine & 3 & 21 & 24 \\
Prednisone & 2 & 20 & 22 \\
NSAIDs & 2 & 2 & 4 \\
Biological treatments & 5 & 14 & 19 \\
Adalimumab & $\mathrm{I}$ & 10 & $\mathrm{II}$ \\
Etanercept & 3 & 0 & 3 \\
Rituximab & $\mathrm{I}$ & 4 & 5 \\
\hline
\end{tabular}

Abbreviations: DMARDs, disease-modifying antirheumatic drugs; NSAIDs, nonsteroidal anti-inflammatory drugs. represented $38.6 \%$ of the study population. There was no statistical difference between the various medication groups and disease activity (Table 3 ).

We analyzed the association of RA disease activity using the DAS28 and other comorbidities including DM, HTN, osteoporosis, CVD, hypothyroidism, and cancer. There was more CVD among the high activity group $(\mathrm{p}<0.001)$ (Table 4).

The median HAQ-DI score for our patients was 0.5. We did not find a statistically significant relationship between the high scores and the type of medication (Table 5). Moreover, there was no statistically significant relationship between HAQ-DI and comorbidities (Table 6).

\section{Discussion}

Given that early diagnosis and prompt management of RA can modulate the erosive and prevalent nature of RA, identification of common variables based on patient demographics and physical examinations is essential. Hence, we conducted this prospective cross-sectional study to classify the most common variables or risk factors related to RA disease activity and remission among RA patients using the DAS28-CRP in evaluating disease activity and remission status in a sample population.

This study was conducted at the King Abdulaziz University Hospital in Jeddah, Saudi Arabia, a country in which the prevalence of rheumatoid arthritis is 2.2 per 1000 cases. ${ }^{15}$ The majority of our study participants were 
Table 3 Patient Medications and Activity Level According to the DAS28-CRP Scale

\begin{tabular}{|l|l|l|l|l|l|}
\hline Medication & Remission & Low Activity & Moderate Activity & High Activity & P-value \\
\cline { 2 - 6 } & No. & No. & No. & No. & \\
\hline DMARDs & 15 & 5 & 28 & 7 & 0.393 \\
Methotrexate & 12 & 4 & 14 & 4 & 2 \\
Leflunomide & 2 & 2 & 8 & 1 & 0.812 \\
Sulfasalazine & 4 & 0 & 14 & 3 & 0.438 \\
Hydroxychloroquine & 5 & 2 & 11 & 2 & 0.231 \\
Prednisone & 8 & 1 & 2 & 0 & 0.432 \\
NSAIDs & 2 & 0 & 6 & 5 & 0.728 \\
Biological & 7 & 1 & 5 & 3 & 0.722 \\
Adalimumab & 3 & 0 & 0 & 0 & 0.137 \\
Etanercept & 2 & 1 & 1 & 2 & 0.289 \\
Rituximab & 2 & 0 & 185 & 0.206 \\
\hline
\end{tabular}

Abbreviations: DMARDs, disease-modifying antirheumatic drugs; DAS28-CRP, Disease Activity Score of 28 joints with C-Reactive Protein.

Table 4 Activity Level and Patient Comorbidities

\begin{tabular}{|c|c|c|c|c|c|c|c|c|c|c|}
\hline & & \multicolumn{2}{|c|}{ Remission } & \multicolumn{2}{|c|}{ Low Activity } & \multicolumn{2}{|c|}{ Moderate Activity } & \multicolumn{2}{|c|}{ High Activity } & \multirow[t]{2}{*}{ p-value } \\
\hline & & No. & $\%$ & No. & $\%$ & No. & $\%$ & No. & $\%$ & \\
\hline Diabetes Mellitus & $\begin{array}{l}\text { Not diseased } \\
\text { Diseased }\end{array}$ & $\begin{array}{l}19 \\
5\end{array}$ & $\begin{array}{l}31 \% \\
36 \%\end{array}$ & $\begin{array}{l}7 \\
0\end{array}$ & $\begin{array}{l}11 \% \\
0 \%\end{array}$ & $\begin{array}{l}28 \\
6\end{array}$ & $\begin{array}{l}46 \% \\
43 \%\end{array}$ & $\begin{array}{l}7 \\
3\end{array}$ & $\begin{array}{l}11 \% \\
21 \%\end{array}$ & 0.466 \\
\hline Hypertension & $\begin{array}{l}\text { Not diseased } \\
\text { Diseased }\end{array}$ & $\begin{array}{l}15 \\
9\end{array}$ & $\begin{array}{l}27 \% \\
45 \%\end{array}$ & $\begin{array}{l}7 \\
0\end{array}$ & $\begin{array}{l}13 \% \\
0 \%\end{array}$ & $\begin{array}{l}25 \\
9\end{array}$ & $\begin{array}{l}45 \% \\
45 \%\end{array}$ & $\begin{array}{l}8 \\
2\end{array}$ & $\begin{array}{l}15 \% \\
10 \%\end{array}$ & 0.239 \\
\hline Osteoporosis & $\begin{array}{l}\text { Not diseased } \\
\text { Diseased }\end{array}$ & $\begin{array}{l}23 \\
1\end{array}$ & $\begin{array}{l}31 \% \\
100 \%\end{array}$ & $\begin{array}{l}7 \\
0\end{array}$ & $\begin{array}{l}9 \% \\
0 \%\end{array}$ & $\begin{array}{l}34 \\
0\end{array}$ & $\begin{array}{l}46 \% \\
0 \%\end{array}$ & $\begin{array}{l}10 \\
0\end{array}$ & $\begin{array}{l}14 \% \\
0 \%\end{array}$ & $0.54 I$ \\
\hline Hypothyroidism & $\begin{array}{l}\text { Not diseased } \\
\text { Diseased }\end{array}$ & $\begin{array}{l}20 \\
4\end{array}$ & $\begin{array}{l}31 \% \\
36 \%\end{array}$ & $\begin{array}{l}5 \\
2\end{array}$ & $\begin{array}{l}8 \% \\
18 \%\end{array}$ & $\begin{array}{l}29 \\
5\end{array}$ & $\begin{array}{l}45 \% \\
45 \%\end{array}$ & $\begin{array}{l}10 \\
0\end{array}$ & $\begin{array}{l}16 \% \\
0 \%\end{array}$ & 0.411 \\
\hline Cardiovascular diseases & $\begin{array}{l}\text { Not diseased } \\
\text { Diseased }\end{array}$ & $\begin{array}{l}23 \\
1\end{array}$ & $\begin{array}{l}33 \% \\
20 \%\end{array}$ & $\begin{array}{l}7 \\
0\end{array}$ & $\begin{array}{l}10 \% \\
0 \%\end{array}$ & $\begin{array}{l}34 \\
0\end{array}$ & $\begin{array}{l}49 \% \\
0 \%\end{array}$ & $\begin{array}{l}6 \\
4\end{array}$ & $\begin{array}{l}9 \% \\
80 \%\end{array}$ & $<0.001$ \\
\hline Cancer & $\begin{array}{l}\text { Not diseased } \\
\text { Diseased }\end{array}$ & $\begin{array}{l}13 \\
1\end{array}$ & $\begin{array}{l}33 \% \\
100 \%\end{array}$ & $\begin{array}{l}3 \\
0\end{array}$ & $\begin{array}{l}8 \% \\
0 \%\end{array}$ & $\begin{array}{l}18 \\
0\end{array}$ & $\begin{array}{l}45 \% \\
0 \%\end{array}$ & $\begin{array}{l}6 \\
0\end{array}$ & $\begin{array}{l}15 \% \\
0 \%\end{array}$ & 0.577 \\
\hline
\end{tabular}

native to Saudi Arabia, followed by Yemenis, Africans, Palestinians, and Asians. The majority of our patients were females with an average age of 49.7 years, and most were married. The average disease duration was 130 days. These demographic data are consistent with previously reported demographics of RA patients in Saudi Arabia. ${ }^{6}$

Using the DAS28-CRP as a predictor to identify low disease activity and remission rates, we found that only $38.6 \%$ (29 patients) had disease remission. This is comparable to the results of Barnabe et al who reported $37 \%$ remission rate. ${ }^{16}$ Conversely, Almoallim et al conducted a study in a tertiary hospital in Saudi Arabia and reported a remission rate of $79.6 \%$ using DAS28-CRP. ${ }^{17}$ This difference can be attributed to an early referral system, as the study was conducted at a private, insurance-based hospital in which the waiting time to access the rheumatology clinic is short compared to that in a general governmental hospital, which requires a longer wait time to access clinics.

The major medications used to treat our sample population were conventional disease-modifying antirheumatic drugs (csDMARDs) in $73.3 \%$ with methotrexate as the most common (45.3\%) followed by hydroxychloroquine (32\%), leflunomide (18.6\%), and sulfasalazine (8\%). Biological treatment was used in $25.3 \%$ of the patients with adalimumab as the most common treatment (14.6\%), followed by rituximab (6.6\%) and etanercept (4\%). These findings are comparable with a similar study conducted in a Saudi private hospital in which csDMARDs were used in 
Table 5 Relationship Between the HAQ-DI Score and Patients' Routine Medications

\begin{tabular}{|l|l|l|l|}
\hline Medication & $\begin{array}{l}\text { Less } \\
\text { Difficulty } \\
\text { (Less Than } \\
\text { Median 0.5) }\end{array}$ & $\begin{array}{l}\text { More } \\
\text { Difficulty } \\
\text { (More Than } \\
\text { Median 0.5) }\end{array}$ & p-value \\
\cline { 2 - 4 } & No. & No. & \\
\hline DMARDs & $3 \mathrm{I}$ & 24 & 0.090 \\
Methotrexate & 17 & 17 & 1 \\
Leflunomide & 6 & 8 & 0.515 \\
Sulfasalazine & 4 & 2 & 0.394 \\
Hydroxychloroquine & 14 & 10 & 0.321 \\
Prednisone & $1 \mathrm{I}$ & $1 \mathrm{I}$ & 0.939 \\
NSAIDs & $\mathrm{I}$ & 2 & 0.539 \\
Biological (Total) & $\mathrm{II}$ & 8 & 0.556 \\
Adalimumab & 7 & 4 & $0.35 \mathrm{I}$ \\
Etanercept & $\mathrm{I}$ & 2 & 0.539 \\
Rituximab & 3 & 2 & 0.714 \\
\hline
\end{tabular}

Abbreviations: HAQ-DI, health assessment questionnaire disability index; DMARDs, disease-modifying antirheumatic drugs; NSAIDs, nonsteroidal antiinflammatory drugs.

$70 \%$ of the patients, whereas the use of non-conventional DMARDs treatment was higher than our study population with tofacitinib as the most common medication followed by adalimumab and etanercept. ${ }^{17}$ Biological and small molecular treatments differ from center to center in the KSA, especially when comparing a private hospital with a general public hospital. Patients in private, insurancebased hospitals have the privilege to access biological treatments more easily and yet, financial issues appear to be a major factor that can interfere with biological treatment compliance in private Saudi hospitals for those not covered by insurance. ${ }^{18}$

Regarding the correlation of the disease activity using the DAS28-CRP with the medications used to treat our patients, $51 \%$ of the patients on csDMARDs had moderate disease activity, whereas those on biological treatment had a $42 \%$ remission rate. Similarly, data from the DANBIO registry in Denmark showed that patients on anti-tumor necrosis factor alpha (anti-TNF $\alpha$ ) had higher remission rates compared to csDMARDs alone. ${ }^{19}$ Consequently, the British Society of Rheumatology recommendations tend toward starting biological treatment during the early course of the disease. ${ }^{20}$

With respect to comorbid diseases, HTN was most commonly observed in our study group, followed by diabetes mellitus, hypothyroidism, osteoporosis, and cancers. However, none of these diseases were significantly associated with RA disease activity. Our findings were consistent with those of another study in which a statistical relationship between HTN and RA was difficult to establish. ${ }^{21}$ This was also consistent with a crosssectional, retrospective analysis of 340 RA patients in Saudi Arabia in which HTN, the most common comorbidity, was present in $35.9 \%$ of the patients followed by DM in $30.9 \%$ and osteoporosis in $25.8 \% .^{6,22}$

Rheumatoid arthritis was associated with a $50 \%$ increased risk of CVD with a relative risk of 1.48 , and indeed, the mortality of rheumatoid patients increased by

Table 6 Relationship Between HAQ-DI Scores and Patient Comorbidities

\begin{tabular}{|c|c|c|c|c|}
\hline & Less Difficulty (Less Than Median) & More Difficulty (More Than Median) & p-value \\
\hline & & No. & No. & \\
\hline Diabetes mellitus & $\begin{array}{l}\text { Not Diseased } \\
\text { Diseased }\end{array}$ & $\begin{array}{l}29 \\
8\end{array}$ & $\begin{array}{l}31 \\
6\end{array}$ & 0.553 \\
\hline Hypertension & $\begin{array}{l}\text { Not Diseased } \\
\text { Diseased }\end{array}$ & $\begin{array}{l}27 \\
10\end{array}$ & $\begin{array}{l}27 \\
10\end{array}$ & 1 \\
\hline Osteoporosis & $\begin{array}{l}\text { Not Diseased } \\
\text { Diseased }\end{array}$ & $\begin{array}{l}36 \\
1\end{array}$ & $\begin{array}{l}37 \\
0\end{array}$ & 0.314 \\
\hline Hypothyroidism & $\begin{array}{l}\text { Not Diseased } \\
\text { Diseased }\end{array}$ & $\begin{array}{l}32 \\
5\end{array}$ & $\begin{array}{l}31 \\
6\end{array}$ & 0.744 \\
\hline Cardiovascular diseases & $\begin{array}{l}\text { Not Diseased } \\
\text { Diseased }\end{array}$ & $\begin{array}{l}36 \\
1\end{array}$ & $\begin{array}{l}33 \\
4\end{array}$ & 0.165 \\
\hline Cancer & $\begin{array}{l}\text { Not Diseased } \\
\text { Diseased }\end{array}$ & $\begin{array}{l}22 \\
0\end{array}$ & $\begin{array}{l}18 \\
1\end{array}$ & 0.276 \\
\hline
\end{tabular}

Abbreviation: HAQ-DI, health assessment questionnaire disability index. 
$39.6 \%$ secondary to $\mathrm{CVD}^{23}$ Moreover, an association between rheumatoid arthritis and cardiovascular diseases, especially ischemic heart disease (IHD), was identified in a cross-sectional study involving 340 Saudi patients. ${ }^{22}$ To investigate the risk factors of CVD in RA, a Swedish casecontrol study on 138 rheumatoid patients found a strong association with high disease activity using DAS28-CRP. ${ }^{24}$ This finding was consistent with our results of strong association between CVD and RA disease activity ( $\mathrm{P}=$ 0.001) (Table 4).

The HAQ-DI is the standard and most commonly used tool for evaluating functional status in RA patients. When HAQ-DI scores were compared with DAS28-CRP scores, the median HAQ-DI score was 0.5 , and the majority of our study population had moderate disease activity based on the DAS28-CRP score. Given that HAQ-DI values from 0 to 1 denote mild to moderate disability, we concluded that the DAS28-CRP scores in our study corresponded to the mean HAQ-DI values. Our findings were contradictory to those of Hansen et al, ${ }^{1}$ who reported that although HAQ values correspond to DAS28 scores among controls, there was no correlation in the patient group. However, this result may be due to the small numbers included in the patient group and their better functional status with moderate activity. Similarly, in the current study, we observed an association between the presence of comorbid diseases such as hypertension and hypothyroidism and higher HAQ-DI values among the sample population (Table 6), which was not statistically significant. Our finding is consistent with that of Krishnan et $\mathrm{al}^{25}$ regarding that advanced age and comorbidities can affect the HAQ-DI scores in patients with RA.

The majority of the study participants with RA were over 40 years of age, and several studies have highlighted that the onset of RA can occur earlier between the ages of 20 and 40 years as well as in older ages ( $\geq 60$ years). ${ }^{26}$ However, a late onset of RA and higher DAS28-CRP and HAQ-DI scores at baseline can result in a higher disease activity, which is consistent with our study sample. ${ }^{27}$

We Identified a higher disease activity, and lower remission rates, among rheumatoid arthritis patients at our center. Fewer patients used biological DMARDs compared to other centers in the same country. Most of our patients are non-Saudi residents who are not covered by governmental insurance for biological treatments, which likely impacted their treatment plans. Participation of private insurance or charities may help these patients achieve a lower disease activity and improve their quality of life.

\section{Limitations}

This study had several limitations. First, a small sample size and single center-based design may have led to a biased result. Second, patient assessment was conducted at only one time point and further follow-ups were not performed due to a lack of resources and funding. However, selection bias was avoided as this study included all RA patients who received medical care from our rheumatology outpatient department, except for second opinion cases who did not receive any medical treatment from our institution.

\section{Abbreviations}

RA, rheumatoid arthritis; KSA, Kingdom of Saudi Arabia; DAS28-CRP, Disease Activity Score-28 for Rheumatoid Arthritis with CRP; EULAR, European League Against Rheumatism; ESR, erythrocyte sedimentation rate; MTX, methotrexate; HTN, hypertension; DM, diabetes mellitus; CVD, cardiovascular disease; CRP, C-reactive protein; ANOVA, Analysis of variance; TJC, tender joint count; SJC, swollen joint count; NSAIDs, nonsteroidal anti-inflammatory drug; csDMARDs, conventional disease-modifying antirheumatic drugs; TNF $\alpha$, tumor necrosis factor alpha.

\section{Data Sharing Statement}

The data is confined to this research, it will not be available in any links or public archived database.

\section{Ethics Approval and Informed Consent}

This study received ethical approval from the ethics committee of King Abdulaziz University (Reference No. 53119), and written informed consent was obtained from all patients included in the study, and it complied with the Declaration of Helsinki.

\section{Consent for Publication}

Written informed consent was obtained from all patients included in the study.

\section{Acknowledgments}

I would like to thank Editage (www.editage.com) for English language editing.

\section{Funding}

The author did not receive any financial support for this work. There is no financial relationship with any organization supporting this work. 


\section{Disclosure}

The author indicates no conflicts of interest.

\section{References}

1. Hansen IMJ, Andreasen RA, van Bui Hansen MN, et al. The reliability of disease activity score in 28 joints-C-reactive protein might be overestimated in a subgroup of rheumatoid arthritis patients, when the score is solely based on subjective parameters: a cross-sectional, exploratory study. $J$ Clin Rheumatol. 2017;23(2):102-106. doi:10.1097/RHU.0000000000000469

2. Van Steenbergen HW, Aletaha D, Beaart-van de Voorde LJJ. EULAR definition of arthralgia suspicious for progression to rheumatoid arthritis. Ann Rheum Dis. 2017;76(3):491-496. doi:10.1136/annrheumdis-2016209846

3. Kleyer A, Finzel S, Rech J, et al. Bone loss before the clinical onset of rheumatoid arthritis in subjects with anticitrullinated protein antibodies. Ann Rheum Dis. 2014;73(5):854-860. doi:10.1136/ annrheumdis-2012-202958

4. Xu B, Lin J. Characteristics and risk factors of rheumatoid arthritis in the United States: an NHANES analysis. PeerJ. 2017;5:e4035. doi:10.7717/peerj.4035

5. Dougados M, Soubrier M, Antunez A, et al. Prevalence of comorbidities in rheumatoid arthritis and evaluation of their monitoring: results of an international, cross-sectional study (COMORA). Ann Rheum Dis. 2014;73(1):62-68. doi:10.1136/annrheumdis-2013-204223

6. Almoallim HM, Alharbi LA. Rheumatoid arthritis in Saudi Arabia. Saudi Med J. 2014;35:1442-1454.

7. Albishri J, Bukhari M, Alsabban A, et al. Prevalence of RA and SLE in Saudi Arabia. Sch J App Med Sci. 2015;3:2096-2099.

8. Almoallim H, Janoudi N, Attar SM, et al. Determining early referral criteria for patients with suspected inflammatory arthritis presenting to primary care physicians: a cross-sectional study. Open Access Rheumatol. 2017;9:81-90. doi:10.2147/OARRR.S134780

9. Almuhareb AM, Alhawassi TM, Alghamdi AA, et al. Prevalence of complementary and alternative medicine use among rheumatoid arthritis patients in Saudi Arabia. Saudi Pharm J. 2019;27 (7):939-944. doi:10.1016/j.jsps.2019.07.002

10. Dargham SR, Zahirovic S, Hammoudeh M, et al. Epidemiology and treatment patterns of rheumatoid arthritis in a large cohort of Arab patients. PLoS One. 2018;13(12):e0208240. doi:10.1371/journal. pone. 0208240

11. Aletaha D, Neogi T, Silman AJ, et al. 2010 Rheumatoid arthritis classification criteria: an American College of Rheumatology/ European league against rheumatism collaborative initiative. Arthritis Rheum. 2010;62(9):2569-2581. doi:10.1002/art.27584

12. Wells G, Becker J, Teng J, et al. Validation of the 28-joint disease activity score (DAS28) and European league against rheumatism response criteria based on C-reactive protein against disease progression in patients with rheumatoid arthritis, and comparison with the DAS28 based on erythrocyte sedimentation rate. Ann Rheum Dis. 2009;68:954-960.

13. Bruce B, Fries JF. The health assessment questionnaire (HAQ). Clin Exp Rheumatol. 2005;23:S14-18.
14. El Meidany YM, El Gaafary MM, Ahmed I. Cross-cultural adaptation and validation of an Arabic health assessment questionnaire for use in rheumatoid arthritis patients. Joint Bone Spine. 2003;70 (3):195-202. doi:10.1016/S1297-319X(03)00004-6

15. Al-Dalaan A, Al Ballaa S, Bahabri S, et al. The prevalence of rheumatoid arthritis in the Qassim region of Saudi Arabia. Ann Saudi Med. 1998;18(5):396-397. doi:10.5144/0256-4947.1998.396

16. Barnabe C, Homik J, Barr SG, et al. The effect of different remission definitions on identification of predictors of both point and sustained remission in rheumatoid arthritis treated with anti-TNF therapy. J Rheumatol. 2014;41(8):1607-1613. doi:10.3899/jrheum.131451

17. Almoallim H, Hassan R, Cheikh M, et al. Rheumatoid arthritis Saudi database (RASD): disease characteristics and remission rates in a tertiary care center. Open Access Rheumatol. 2020;12:139-145. doi:10.2147/OARRR.S260426

18. Eleishi HH, Toma NF, Chaki MC, et al. Three years experience with the prescription of anti-TNF- $\alpha$ inhibitors at Dr Soliman Fakeeh Hospital in Jeddah, Saudi Arabia. Int J Rheum Dis. 2009;12 (1):14-19. doi:10.1111/j.1756-185X.2009.01373.x

19. Hetland ML, Christensen IJ, Tarp U, et al. Direct comparison of treatment responses, remission rates, and drug adherence in patients with rheumatoid arthritis treated with adalimumab, etanercept, or infliximab: results from eight years of surveillance of clinical practice in the nationwide Danish DANBIO registry. Arthritis Rheum. 2010;62:22-32.

20. Hyrich KL, Watson KD, Lunt M, et al. Changes in disease characteristics and response rates among patients in the United Kingdom starting anti-tumour necrosis factor therapy for rheumatoid arthritis between 2001 and 2008. Rheumatology (Oxford). 2011;50 (1):117-123. doi:10.1093/rheumatology/keq209

21. Manavathongchai S, Bian $\mathrm{A}$, Rho $\mathrm{YH}$, et al. Inflammation and hypertension in rheumatoid arthritis. $J$ Rheumatol. 2013;40 (11):1806-1811. doi:10.3899/jrheum.130394

22. Al-Bishri J, Attar S, Bassuni N, et al. Comorbidity profile among patients with rheumatoid arthritis and the impact on prescriptions trend. Clin Med Insights Arthritis Musculoskelet Disord. 2013;6:11-18. doi:10.4137/CMAMD.S11481

23. England BR, Thiele GM, Anderson DR, et al. Increased cardiovascular risk in rheumatoid arthritis: mechanisms and implications. $B M J$. 2018;361:k1036. doi:10.1136/bmj.k1036

24. Mantel Ä, Holmqvist M, Nyberg F, et al. Risk factors for the rapid increase in risk of acute coronary events in patients with new-onset rheumatoid arthritis: a nested case-control study. Arthritis Rheum. 2015;67(11):2845-2854. doi:10.1002/art.39267

25. Krishnan E, Häkkinen A, Sokka T, et al. Impact of age and comorbidities on the criteria for remission and response in rheumatoid arthritis. Ann Rheum Dis. 2005;64(9):1350-1352. doi:10.1136/ ard.2005.037903

26. Horiuchi AC, Pereira LHC, Kahlow BS, et al. Rheumatoid arthritis in elderly and young patients. Rev Bras Reumatol Engl Ed. 2017;57 (5):491-494. doi:10.1016/j.rbr.2015.06.005

27. Innala L, Berglin E, Möller B, et al. Age at onset determines severity and choice of treatment in early rheumatoid arthritis: a prospective study. Arthritis Res Ther. 2014;16(2):R94. doi:10.1186/ar4540 


\section{Publish your work in this journal}

Open Access Rheumatology Research and Reviews is an international, peer-reviewed, open access journal publishing original research, reports, editorials, reviews and commentaries on all aspects of clinical and experimental rheumatology in the clinic and laboratory including the following topics: Pathology, pathophysiology of rheumatological diseases; Investigation, treatment and management of rheumatological diseases; Clinical trials and novel pharmacological approaches for the treatment of rheumatological disorders. The manuscript management system is completely online and includes a very quick and fair peer-review system, which is all easy to use. Visit http://www.dovepress.com/testimonials.php to read real quotes from published authors. 